\title{
Acercamiento literario y biográfico a Pedro Ángel de Gorostiza y Cepeda: documentos y pistas sueltas
}

Alfonso Saura Universidad de Murcia

Cuando analicé hace unos años la labor traductora del misterioso Pedro Gorostiza o Pedro Ángel de Gorostiza y Cepeda (Saura: 707-716), hermano del más conocido Manuel Eduardo de Gorostiza, llegaba a la conclusión de que se trataba de "un buen traductor de teatro", que conocía bien la lengua y la literatura francesas y que las vertía al castellano "con claridad y precisión". Llegaba a estas conclusiones después de haber analizado las dos traducciones editadas con su nombre: Luis Onceno, tragedia en cinco actos, $1836,{ }^{1}$ e Hija, esposa y madre, comedia en tres actos, $1838 .^{2}$ En la primera demostraba su dominio de la versificación castellana; en la segunda, en prosa, no sólo mantenía la exactitud sino que buscaba mejoras estilísticas en réplicas, giros y expresiones. Terminaba aquel artículo expresando mi deseo de profundizar en la identidad del personaje y en las circunstancias que lo llevaron a aprender el oficio. Hoy, gracias a los benditos archivos, puedo ya añadir datos perfectamente documentados que iluminan algunos aspectos de su vida. Datos que resaltan, en paralelo, lo mucho que ignoramos. Estoy seguro de que nuevas búsquedas aportarán documentos que completen su semblanza.

Tal indagación nos es necesaria no sólo para el conocimiento de esta figura como dramaturgo español, sino también para esclarecer datos y

\footnotetext{
${ }^{1}$ Es traducción de Louis XI, tragédie en 5 actes et en vers, par M. Casimir Delavigne. Paris: Barba, 1832.

${ }^{2}$ Es traducción de Marie ou Trois époques, comédie en trois actes, en prose, par Mme Ancelot... Paris: Magasin Théâtrale, 1836.
} 
aspectos biográficos relativos a su hermano Manuel Eduardo, quien, en 1824 cuando se hallaba en Londres durante el destierro al que le obligó Fernando VII, eligió la ciudadanía mexicana por la vía de los hechos, apelando a su nacimiento en Veracruz. Lo que se averigüe acerca de uno de los dos hermanos contribuirá seguramente a delinear mejor la trayectoria del otro, aun cuando sus destinos hayan sido distintos, puesto que el uno permaneció en España, y el otro se decidió a colaborar en la construcción del México independiente, incluyendo sus actividades teatrales.

Pero ¿qué sabíamos hasta hace poco? Que Pedro Gorostiza y Cepeda, oscuro hermano del más conocido Manuel Eduardo, había sido traductor y autor original entre 1836 y 1838 , y que se le atribuía a él la verdadera identidad oculta bajo el pseudónimo de Ángel de Cepeda.

En efecto, Pedro Gorostiza había aparecido por vez primera en el mundo literario de Madrid en agosto de 1833 bajo el pseudónimo de Ángel de Cepeda. Tal era el pseudónimo con el que firmó el opúsculo Defensa de la comedia intitulada Contigo pan y cebolla, ${ }^{3}$ que había sido criticada por Fígaro, es decir Larra, en la Revista Española del 9 de julio. La publicación de dicha Defensa debió de ser muy rápida, porque el 13 de agosto la misma Revista Española hacía pública una "Réplica al folleto titulado 'Defensa de la comedia Contigo Pan y Cebolla'". Las críticas de Larra debieron molestar mucho a nuestro Pedro Ángel, puesto que éste focalizó en aquél todas las críticas recibidas — también las hubo en otros periódicos- y a él se dirigió expresamente como "el que lleva el juego" (Cepeda 1833: 4). Lo que no sabemos es si había habido algo más, quizás personal, antes de este estallido.

Antes de concluir, Ángel de Cepeda recuerda que se ha visto obligado a responder. Si leemos con detenimiento, observamos su declaración de parentesco de sangre con Manuel Eduardo de Gorostiza:

${ }^{3}$ Defensa de la Comedia intitulada Contigo pan y cebolla, contra las criticas que han hecho de ella los periódicos de Madrid. Dirigida a los redactores de la Revista Española por Don Ángel de Cepeda. Madrid, Imprenta de Repullés, Agosto de1833. Manuel Eduardo, exiliado, que ya ha preparado otra edición en Londres (Cunningham y Salmon) va camino de América en esa fecha. La edición de Madrid en 1833 también la hizo Repullés. Su hermano debía ser su agente literario en Madrid. Curiosamente el único ejemplar de la edición de 1833 en Londres que conserva la BNE (sig: 2/56319) se halla encuadernado formando un solo volumen con la edición de 1822 de las Poesías del ilustre colombiano José Fernández Madrid. El tomo lleva ex-libris de Gayangos, pero va firmado por J.O. Seaton a 3 de febrero de 1875 . 
En cuanto a mí, bien sabe Dios que ninguna gana tenía de salir a la palestra, y si fuese mía la obra, no me defendería aunque me hubieran puesto ustedes como hoja de perejil. Esto mismo ofrezco hacer, si por mi desgracia llega el caso; pero en la ocasión presente me he obligado a volver por una persona que está muy lejos de aquí, y con la cual me unen los más sagrados vínculos (Cepeda 1833: 30).

Para Dowling, Contigo pan y cebolla, entendida como farsa, "tiene rasgos geniales" (18) y "posee la alegría, la risa y la carcajada, y los elementos inverosímiles de la buena farsa. En su género es una obra maestra de la literatura hispánica” (20). Mi pregunta sería saber cómo la leyeron, entendieron y ensayaron los actores de Madrid ante la lejanía del autor que vivía en México. En todo caso el público, lejano a las discusiones eruditas, la disfrutó tanto en Madrid aquel julio como la disfrutaría en México en diciembre.

Ángel de Cepeda volvería a aparecer un par de años después como el habilidoso traductor de Lucrecia Borgia, el primer drama de Hugo representado en Madrid $^{4}$ el sábado 18 de julio de 1835, que alcanzó notorio triunfo $^{5}$ y simboliza la entrada en la escena española del romanticismo francés traducido. ${ }^{6}$ El profesor Ermanno Caldera -que no creía en la existencia de Ángel de Cepeda y lo identificaba simplemente con Manuel

${ }^{4}$ El profesor Louis Miard estudió "Les premières de Lucrèce Borgia de Victor Hugo, en Espagne et au Portugal" (in Interférences, no 4, 1977. 48-62). A pesar de algunos errores en las fechas de los periódicos, allí podemos ver cómo se prepara al público lector para la representación de esta novedad dramática.

${ }^{5}$ Según la Cartelera Teatral Madrileña más de 20 representaciones entre 1835-1838. Fue el mayor éxito de Hugo, más que Angelo (agosto 1835) o cualquier otra posterior (Hernani, Maria Tudor).

${ }^{6}$ La primera traducción de Dumas representada es Ricardo Darlington en septiembre del 35. El gran éxito de Dumas, Margarita de Borgoña (La Tour de Nesle traducida por A. García Gutiérrez), es de octubre de 1836. Para una visión de conjunto de la recepción de la obra de Alejandro Dumas en España se debe consultar Angels Santa, "Quelques considérations sur la réception d'Alexandre Dumas père en Espagne”, in Oeuvres et Critiques XXI, 1 (1996). 43-54. Acerca de Ricardo Darlington se podrá consultar mi artículo "Jose Andrew de Covert-Spring traductor de Dumas: Ricardo Darlington”, en Angels Santa y F. Lafarga (eds.), Alexandre Dumas y Victor Hugo. Viaje de los textos y textos de viaje, Lleida: Universitat-Pagès, 2006. Covert-Spring (es decir José Andreu y Fontcuberta) también es el primer traductor (1835) de Anthony de Victor Hugo bajo el disimulado título de Zelmiro. La conocida versión de Ochoa, Anthony, es de 1839. 
Eduardo de Gorostiza-7 en su artículo "La Lucrecia Borgia que se estrenó en el Teatro del Príncipe" hizo un cuidadoso examen de esta traducción. La pieza salió "traducida libremente" "lo cual significa" —en palabras del mismo Caldera - "que el traductor corta, añade, modifica, retoca y se siente autorizado a cambiar nombres, fechas, títulos" (Caldera: 247). Ciertamente gran parte del éxito de esta pieza estribaba en el tino con que fue traducida. La Revista Española del 20 de julio, tras hacer un largo resumen de la trama, concluye con este párrafo final:

No se desanime la empresa en darnos esta clase de traducciones, ya que nos haya de dar algunas: preséntelas en la escena con cuidado igual al que ha puesto en Lucrecia Borja; desempéńenlas los actores tan bien como han desempeñado la obra del primer romántico francés, y la educación romántica y el buen gusto, y la inteligencia en cosas de literatura se irá formando en el público. Estamos al principio de la carrera: confundimos el romanticismo con los horrores y los crímenes, que creemos indispensables para él, no le hemos sabido tomar el gusto desentrañando su mérito, y tantos obstáculos solo pueden vencerse con la repetición de buenos modelos (Revista Española, 20-VII-1835, nº 142).

La traducción de Cepeda también fue alabada por La Abeja en su crítica del estreno:

No acabaremos este artículo sin elojiar la traducción, que según dicen, es de Don Pedro Gorostiza. Está hecha con tal conocimiento del teatro y en tan castizo lenguaje que parece obra orijinal (La Abeja, 21-VII-1835. 1).

En efecto Pedro Ángel de Gorostiza y Cepeda no solo dominaba ambas lenguas sino que sabía cómo dar el tono adecuado para introducir a Victor Hugo entre el público madrileño. Todo un testimonio del oficio de traducir.

El nombre de Ángel de Cepeda desaparece en 1835, pero le toma el relevo el de Pedro Gorostiza e incluso Pedro de Gorostiza y Cepeda ${ }^{8}$ con cuatro obras. Bajo este nombre se estrenan y editan en Madrid las si-

7 "Autor de la traducción era Ángel de Cepeda, o sea Manuel Eduardo de Gorostiza que ya en otras ocasiones se había ocultado detrás de ese seudónimo" (Caldera 247). El "otras veces" es alusión al folleto de 1833. Más tarde lo llama el "seudo-Cepeda" (251).

${ }^{8}$ Cuando la Revista Española (Vol. VIII, 12, VI, 1836) da cuenta de la primera representación de Luis XI, dice que es drama escrito en francés por Casimiro Delavigne y traducido al castellano por D. Pedro Gorostiza y Cepeda. 
guientes obras de teatro: Luis Onceno, 1836, tragedia, 5 actos en verso, traducida de Louis XI, de Casimir Delavigne; El Desconfiado, 1837, comedia, 5 actos en verso, original; Pedrarias Dávila, 1838, drama, 5 actos en verso, original; y finalmente Hija, esposa y madre, 1838, drama, 3 actos en prosa, traducida de Marie ou Trois époques, de Mme Ancelot. Ninguna tuvo un éxito brillante, aunque se introdujeron en el repertorio. ${ }^{9}$ Luis Onceno se estrenó en el Teatro del Príncipe el 9 de abril de 1836 (Cartelera 45) con regular éxito puesto que no se repitió función al día siguiente, sino el 22 y 23 de octubre y el 14 de diciembre, siempre en el Príncipe (Cartelera 48-9). El Desconfiado se estrenó el 25 de diciembre de 1837 en el Príncipe y se repitió el 26 (Cartelera 55) y el 28 de enero de 1838. Según la Gazeta de Madrid del 8 de enero es una comedia de costumbres "nombre que aterroriza y horripila a los nuevos sectarios de la escuela del romanticismo francés" (Veinticuatro Diarios II, 382, no 9135). Hija, esposa y madre, se estrenó igualmente en el Príncipe el 15 de febrero de 1838 y repitió los dos días siguientes (Cartelera 57-58). La Gazeta de Madrid del 24 de febrero la califica de comedia sentimental que no llena las condiciones del drama moderno, alaba su conocimiento del corazón humano y la contrapone a Anthony como ejemplo perverso (Veinticuatro Diarios II, 382, no 9136). No tengo referencias del estreno de Pedrarias Dávila, porque en la Cartelera Teatral Madrileña no aparece. Pero la Gazeta de Madrid de 21 de mayo de 1839 señala su "interés y moralidad” y su magnífica versificación (Veinticuatro Diarios II, 382, nº 9137). Me interesa hacer observar que la producción dramática firmada por Pedro Gorostiza se concentra en 3 o 4 ańos y que no tenemos otras obras suyas anteriores o posteriores. Son cuatro piezas, dos originales y dos traducidas, tres en verso y una en prosa, dos históricas - una calificada de tragedia, otra de drama y situada en América- ${ }^{10} \mathrm{y}$ dos de costumbres contemporáneas de fuerte carácter sentimental.

${ }^{9}$ Luis Onceno parece ser su éxito más duradero. Gracias a Veinticuatro Diarios sabemos que en septiembre de 1850 se preparaba su reposición en el Teatro Español (Veinticuatro Diarios I, 125, no 2945-6), y que la compañía de Valero la llevaba en su gira por provincias: en julio de 1850 en La Coruña (Veinticuatro Diarios II, 418, no 10028), en diciembre de 1851 en Córdoba (Veinticuatro Diarios III, 76, n 1733). Por otra parte es su única obra reeditada.

${ }^{10}$ De los 5 actos (el cuarto dividido en 2 cuadros según la última moda del momento) de Pedrarias Dávila, los tres primeros se localizan en una isla en el golfo de México, el $4^{\circ}$ en el Darién y el $5^{\circ}$ en Panamá. Por supuesto salen españoles e indios. 
Si unimos la producción publicada de Ángel de Cepeda a la de Pedro Gorostiza, tenemos una vida literaria concentrada entre los ańos 1833 y 1838. Ni antes ni después. Un momento clave en el romanticismo español que merece un estudio profundo y detallado de la participación, postura y contradicciones, si las hubiera, de nuestro autor. Poco hemos avanzado sobre la vieja afirmación de don Julio Cejador en 1917:

Pedro de Gorostiza y Cepeda, hermano de Manuel Eduardo, por seud. Angel Cepeda, publicó Defensa de la comedia "Contigo pan y cebolla", 1833. Lucrecia Borgia, dr. (trad.), 1835. Luis Onceno (trad.), 1836. Estreno de El Desconfiado, com., 1837. Pedrarias Dávila, dr., 1838. (Cejador: VII, 176).

Y, sin embargo, este cincuentón que domina el oficio de escribir, tuvo que tener una vida propia anterior, que haber leído y gustado de la literatura tanto en español como en francés, que haberse ejercido en el verso castellano, etc. ¿Qué fue de él antes y después de estas fechas? A partir de lo que sabemos sobre su hermano y su padre hemos ido rebuscando en los archivos y hemos encontrado documentos que nos han permitido avanzar con datos precisos.

Mucha es la información conservada en los archivos sobre su padre, buen servidor del rey, que murió tempranamente en 1794 siendo mariscal y gobernador de Veracruz.

El nombre completo y genealogía de éste lo conocemos por el expediente de concesión del título de Caballero de Santiago en $1772 .{ }^{11}$ A 7 de noviembre de 1772, el rey firmó el título de concesión a don Pedro José Fernández de Gorostiza, teniente coronel y sargento mayor del regimiento de infantería de América, natural del valle de Orozco, en el señorío de Vizcaya. Pero antes de recibir tal distinción y muestra del aprecio del rey había que demostrar, en aquella sociedad de castas, la limpieza de sangre, para lo cual se elaboraba un expediente en la escribanía misma de la Orden. El documento primero es la cédula de merced del hábito de Santiago y está fechado en San Ildefonso a 24 de julio de 1772. Allí nos enteramos de que "atendiendo al mérito y servicios" que concurrían en el interesado, "por decreto del 18 de julio de este año", el rey le concedió "hábito en una de las órdenes militares sin exceptuar la de

\footnotetext{
${ }^{11}$ AHN (Archivo Histórico Nacional de Madrid)). Sección de Órdenes Militares, Expedientillos, no 8135 .
} 
Santiago" y que "habiendo elegido el de Santiago", etc. se le expide la cédula. El segundo documento es una declaración de Pedro Gorostiza ante notario y testigos firmada por todos ellos en San Roque ${ }^{12}$ a 10 de agosto de 1772. Declara el nombre de sus padres y abuelos y sus respectivos lugares de nacimiento. Gorostiza precisa que no puede presentar documentos "por falta de circunstancia"13 y que "no reside en Indias". Por este documento sabemos que fue hijo de Miguel Antonio de Gorostiza, natural de Logrońo, reino de Castilla, y de Ignacia Antonia de Lorca, natural del lugar de Villaro ${ }^{14}$ en dicha provincia de Vizcaya. Que sus abuelos paternos fueron Tomás Fernández Gorostiza, natural de la Puebla de Arganzón, reino de Castilla, y Ana Gonzalez de Vírgala, natural del lugar de Logroño, reino de Castilla. Y los maternos: Domingo de Lorca, natural de Villa Mayor, ${ }^{15}$ Reino de Navarra y Ana de Egusquiza, natural de Barbarín, reino de Navarra. Todos nacidos, como vemos, en tierras muy próximas y reputados de cristianos viejos. Pero nos ayuda a hacernos una idea del padre: joven oficial prometedor, salido de una familia de hidalgos, nobleza menor obligada a emigrar, pero que procuraba hacerlo en las mejores condiciones posibles. Fueron un semillero de servidores de la Corona; y Carlos III, como ilustrado, supo premiarlos y promoverlos. Por los movimientos de su padre y abuelo, suponemos que ya formaban parte del incipiente funcionariado. No imaginamos grandes mayorazgos ni haciendas tras esos nombres.

Los documentos tercero y cuarto no nos informan de nada nuevo. Son informes genealógicos (firmados por Antonio de Zeballos) y recibos de dietas y otros pagos por la formación del expediente. Nos hemos quedado sin saber la fecha de nacimiento del padre que suponemos anterior a 1750 .

12 San Roque está a las puertas de Gibraltar y era un lugar estratégico. Cuando el rey perdió y luego cedió a Inglaterra el Peñón en virtud de tratados internacionales, la Ciudad y Concejo de Gibraltar se retiró simbólicamente al interior, a la ermita de San Roque.

${ }^{13}$ La ambigüedad de la frase hecha no oculta la rapidez con que se llevaba esta concesión. Alguien debió solicitar —o apoyar fuertemente- la concesión en la corte y elegir en su nombre Santiago antes de una semana. Rápido fue también el envío de esta declaración, quince días después, desde los muros de Gibraltar donde residía su regimiento. Del mismo modo la ausencia de partidas de nacimiento indica rapidez y favor.

${ }^{14}$ Villaro (fundada como Villa de Haro) era famosa por su balneario.

${ }^{15}$ Supongo que Villamayor de Monjardín, al noroeste de Logroño. 
Las informaciones sobre su madre, María del Rosario Cepeda, y familia materna nos lo ha proporcionado otro expediente de Santiago, el de pruebas para contraer matrimonio con un caballero de esta Orden. ${ }^{16}$ El expediente se inicia con la petición de permiso por parte del caballero y el pago de 20 ducados de plata. Aquí sí hay partida de nacimiento, informantes de calidad, nuevos pagos y un permiso, por fin, concedido por el Consejo, a 31 de octubre de 1774. De todo ello sacamos que María del Rosario, Dolores, Petronila, Gonzaga, nació el 10 de enero de 1756, que fue bautizada en la parroquia del Sagrario de Cádiz por fray Juan Evangelista de Sevilla, capuchino, custodio de su provincia ${ }^{17}$ y calificador de la Inquisición; que era hija legítima de don Francisco de Cepeda y dońa Isabel Ruiz Barroz; ${ }^{18}$ que sus abuelos paternos eran Lázaro de Cepeda y Guerrero e Isidora Barchete y Peña, naturales ambos de esta ciudad de Cádiz; y los maternos Marcos Ruiz y Ana Barroz y Falcón, naturales de la ciudad de Sevilla. El testimonio de los informantes nos garantiza que todos ellos son "tenidos de legítimos matrimonios sin mezcla alguna de bastardía o ilegitimidad. Y que son limpios y christianos viejos libres de toda mácula y tara de judío, moro o converso". ${ }^{19}$

Igualmente nos informan que Francisco de Cepeda, padre de la novia, era caballero de la orden de Calatrava y regidor perpetuo de Cádiz. ${ }^{20}$ Esto quiere decir que pertenecen a familia patricia y de dineros reposados. También con alianzas en los ejércitos —oficio de hidalgos- especialmente en la Armada. María del Rosario era una jovenzuela de 18 años a la que no faltarían pretendientes. Se viene repitiendo que por su triunfo a los 12 años en un concurso escolar, Cádiz la nombró regidora honoraria de la ciudad de Cádiz. Ciertamente con este título aparece en Veracruz en la partida de nacimiento de su hijo Manuel María del Pilar

\footnotetext{
${ }^{16}$ AHN (Archivo Histórico Nacional de Madrid), Órdenes Militares, Casamientos, Santiago, no 10078 .

${ }^{17}$ En la ciudad de Cádiz los capuchinos eran la orden más importante y su superior un auténtico poder fáctico.

${ }^{18}$ Unifico las grafías de Varroz y Barroz, al igual que las de Zepeda y Cepeda.

${ }^{19}$ Poder aplicar esta fórmula —o sus ligeras variantes - era la finalidad del expediente.

${ }^{20}$ Regidor y no corregidor como he leído en algún sitio. Mientras los regidores formaban un colegio limitado de patricios (caballeros veinticuatro se llamaban en algunas ciudades, por ser éste su número) y cada uno de ellos representaba a su poderosa familia, los corregidores eran funcionarios del rey cuya jurisdicción representaban.
} 
Eduardo. Sea más o menos cierta la anécdota escolar, su educación debió ser esmerada en la ciudad más rica, culta y progresista de Espańa en el siglo XVIII. Esta familia gaditana, sus parientes y aliados, debieron acoger y proteger a la viuda y huérfanos en dos ocasiones: en 1795, a su regreso de Nueva España, y en 1810, cuando toda la península, menos Cádiz, estaba en manos de Napoleón y Manuel Eduardo, al menos, era un activo constitucionalista que empezaba a escribir en los periódicos. Todos los informantes sobre la señorita Cepeda concluyen en que ésta se puede casar con el caballero de Santiago "dada su calidad".

Sobre la carrera y actividad militar de Pedro Fernández de Gorostiza tenemos abundantes datos. Por el índice de manuscritos de la Real Biblioteca (sig. II/2856-6), sabemos que en 1776 don Pedro de Gorostiza dirigió a don José Gálvez un plan para la formación de pié de tropa veterana en Nueva España. Ignoro si con este motivo viajó a Indias. Su nombramiento en 1789 como gobernador de Veracruz e inspector general de las tropas de Nueva España, produjo abundante documentación. El más interesante para nuestro tema es el expediente de información y licencia de pasajero a Indias (Archivo General de Indias, Contratación, 5533, N.3, R.9) iniciado a 31 de mayo de 1789 . Sabemos que viaja con su mujer e hijos - Francisco y Pedro- y sus criados, entre los cuales hay un negro y una negra libres. ${ }^{21}$ Desdichadamente no aparece la edad de sus hijos, ${ }^{22}$ aunque sabemos por testimonio — que luego veremos- del mismo Pedro Ángel que nació en 1786 y que Manuel Eduardo ya viajó en el vientre de su madre y nació aquel 13 octubre en Veracruz.

\footnotetext{
${ }^{21}$ Se trata de Francisco Javier Gorostiza, "moreno" libre, de 36 ańos, casado, y de Agustina Campana, "morena" libre, de 30 años, casada. No sabemos cuándo los adquirió o libertó, como sugiere el nombre del primero. ¿Hubo un viaje anterior a Indias? Por otra parte el puerto mismo de Cádiz proporcionaba la ocasión. La presencia de esclavos moros o negros en tareas domésticas era señal de distinción entre las clases altas. Con frecuencia eran liberados, pero seguían al servicio de la familia. En cuanto a los otros cuatro "criados" — dos hombres y dos mujeres— , todos eran naturales de la península, jóvenes —entre 22 y 29 ańos- y solteros, y podían desempeñar diversas funciones, no forzosamente serviles. Su incorporación al séquito del nuevo gobernador podía representar una buena manera de emigrar a Indias.

${ }^{22}$ La hoja va escrita y firmada por don Pedro y sólo cita "mi mujer [...] mis hijos".
} 
Don Pedro Gorostiza murió a las doce horas y doce minutos el 9 de noviembre de 1794 "después de una dilatada y penosa enfermedad". ${ }^{23}$ Así consta en la carta de don Pedro Ponce dirigida a Godoy, ya titulado duque de Alcudia, en la que le hace saber que está desempeñando el mando por fallecimiento de Gorostiza, cuyos tres empleos enumera (Archivo General de Indias, Estado, 35, no 7). La información se reitera en la carta reservada del nuevo virrey, marqués de Branciforte, ${ }^{24}$ al mismo Godoy en la que le comunica igualmente que provisionalmente ha agregado la subinspección al virreinato y ha encargado la gobernación e intendencia de Veracruz al oficial de mayor graduación, el coronel de ingenieros, don Pedro Ponce (Archivo General de Indias, Estado, 22, $\mathrm{n}^{\mathrm{o}}$ 58). Así se resuelve — con racionalidad, ciertamente— la sustitución del funcionario fallecido. Deja viuda y tres hijos pequeños. Pedro Ángel tiene 8 años, Manuel Eduardo 5, y del mayor, Francisco, ignoro la edad. Tampoco sé si éste tenía mayorazgo que heredar.

Viuda y huérfanos regresan a España, precisamente a Cádiz dónde la familia materna tuvo que acogerlos al menos en un primer momento. Se ha dicho que regresaron en el mismo barco que Revillagigedo, cosa muy posible por las fechas ${ }^{25}$ y nueva señal de amistad y protección para la familia. ${ }^{26}$ En 1798 el rey concedió a dońa María del Rosario Cepeda una pensión sobre vacantes mayores (Archivo General de Simancas, Secretaría de Guerra, 6844, exp.149, f. 589). Han pasado ya casi cuatro años

${ }^{23}$ Dowling establece la fecha de su muerte el 8 de noviembre (21). Ignoro su fuente, que puede ser de origen familiar.

${ }^{24}$ Branciforte era cuñado de Godoy (casado con su hermana María Antonia) y había sustituido a Revillagigedo en julio de 1794 de manera poco elegante y desconsiderada con el buen servidor de la Corona. Godoy había sustituido a Aranda como primer secretario de Estado en 1792 y ya en 1793 había previsto esta sustitución como parte de su política de nepotismo y clientelismo.

${ }^{25}$ Revillagigedo no se apresuró a regresar a la península, sino que permanecía en tierras mexicanas para disgusto de su sucesor, quien a su vez lo urgía a regresar. Por fin zarpó el 22 de diciembre de 1794 (Calderón: 350), 43 días después de la muerte de su amigo y colaborador. Tras su escala en La Habana, partió de ésta el 28 de enero de 1795. Se conserva una carta fechada el 19 de abril en Cádiz en la que expresa su deseo de que se le permita viajar a la Corte para besar la mano (351) del rey. En una nueva afrenta, no fue autorizado hasta mucho después.

${ }^{26}$ Es posible que "la dilatada y penosa enfermedad" de su amigo Gorostiza fuese una de las razones de su retraso. Tras su entierro, nada retenía ya en Nueva Espańa a Revillagigedo ni a la familia del muerto. 
desde la muerte del mariscal de campo que tantos servicios prestó a la Corona. ${ }^{27}$ Aún quedaba por resolver el futuro de los hijos.

De doña Rosario también sabemos que se estableció en Madrid y participó en junta de damas de la Real Sociedad Económica de Madrid, lo que es señal de cierto activismo ilustrado. Así lo atestigua un manuscrito de 1806 conservado en el palacio de Oriente: "Extracto de las tareas realizadas por la Junta de Damas de honor y mérito de la Sociedad Económica de Madrid" (Real Biblioteca, Manuscritos, Sig. II/3564). El f. 12v lleva la firma de la secretaria, dońa María Rosario Cepeda y Gorostiza. Está fechado a 15 de marzo de 1806 . Una señora cultivada; no todo era ignorancia y reacción en vísperas de la ocupación francesa.

Se ha venido repitiendo que los tres hermanos Gorostiza tomaron el oficio de las armas como su padre, que Francisco heredó el mayorazgo y que Manuel Eduardo no quería ser clérigo.

No tenemos la partida de nacimiento de Pedro Ángel. Aceptamos que nació en 1786 según su propio testimonio que ya se verá, pero no sabemos si en Cádiz, donde residía la familia materna, o en otro lugar donde estuviera destinado su padre. El supuesto paso de Manuel Eduardo por la escuela de pajes de Carlos IV nos ha llevado a consultar el Archivo de Palacio. Allí sólo hay datos de Pedro Ángel, quien, como veremos más adelante, siempre se sintió ufano y lo unió a sus méritos. En efecto, en el libro de registro y órdenes de su majestad y el caballerizo mayor a la Casa de Pajes, ${ }^{28}$ queda anotado a 8 de julio de 1798, el comunicado de Jovellanos haciendo saber que por orden del rey la primera plaza vacante será para nuestro Gorostiza:

${ }^{27}$ No tenemos documentos de las razones de este retraso (¿parte de la inquina contra Revillagigedo?) ni de su desatasco bajo el ministerio de Jovellanos.

${ }^{28}$ El Archivo de Palacio contiene abundante información redundante. El libro de registro citado es el no 01372 y contiene las órdenes recibidas entre 1782 y 1804 . Lleva un índice al principio de la encuadernación que se reveló poco de fiar por incompleto. El no 01373 (de 1804 a 1829) es continuación del anterior y cierra la historia de esta institución. Es la serie más completa y la que nos ha servido de base. La información se duplica en parte con el libro $\mathrm{n}^{\circ} 01367$, registro copiador de órdenes relacionadas con la casa de pajes (de 1767 a 1814d). En este libro se asume la legalidad de la regencia de la junta suprema central y demás gobiernos soberanos porque el libro viaja a Cádiz, donde se fechan y firman órdenes, y luego vuelve a Madrid donde se cierra a 18 de abril de 1814 . Todavía hay una tercera fuente de información, el libro $\mathrm{n}^{\circ}$ 01370, registro copiador de órdenes dadas por el caballerizo mayor a la casa de pajes (de 1767 a 1824) que, como en la actual burocracia, repite la información desde otro lugar de trabajo. 
Excmo. Sr: Atendiendo el Rey al mérito y servicios del Mariscal de Campo de sus Reales ejércitos D. Pedro Gorostiza, Gobernador, Intendente y Subinspector que fue de las tropas de Nueva Espańa, y a la situación en que ha quedado su viuda Dña. Maria del Rosario Cepeda: (sic) ha venido S. M. en conceder a su hijo D. Pedro Ángel la primera plaza de Caballero Page que vaque: y de orden de S. M. lo participo a V. E. para su inteligencia y cumplimiento. Dios guarde a V. E. muchos ańos. Palacio 8 de julio de 1798. Gaspar de Jovellanos. Señor Marqués de Bélgida (Registro 01372, Folio 147v).

Jovellanos era ministro de Gracia y Justicia desde noviembre de 1797 y sus comunicados a la Casa de Pajes aparecen registrados desde marzo del 1798. El marqués de Bélgida era desde abril de ese año el nuevo caballerizo mayor, en sustitución del marqués de Villena que lo había sido muchos ańos. El caballerizo mayor formaba parte de la corte y con ella se desplazaba en torno al rey, pero de él dependía la Casa de Pajes que estaba en Madrid. Queda claro que por fin alguien había movido los hilos para proteger a la familia del buen servidor, puesto que la fecha coincide con la pensión a la viuda. Sin embargo, que la reserva de plaza se haga a favor del segundo hijo y no del primero, del huidizo Francisco, ${ }^{29}$ me plantea por qué éste había quedado descartado. ¿Se le consideraba protegido por un mayorazgo? ¿Era demasiado mayor? ¿Tenía otro empleo?

La vacante en la Casa de Pajes se produjo aquel mismo noviembre. ${ }^{30}$ Pedro Ángel tendría sólo 12 años y permaneció allí formándose casi cuatro años hasta que en junio de 1802 fue destinado como capitán al regimiento del príncipe. Este regimiento residía en Madrid y se consideraba el primer regimiento de infantería entre las numerosas tropas de la Corona. ${ }^{31}$ La mano del monarca favoreció de nuevo a los Gorostiza.

${ }^{29}$ Nada he encontrado de él.

${ }^{30}$ Con fecha 11 de noviembre de 1798, Jose Antonio Caballero participa por orden del rey al marqués de Bélgida el nombramiento de Pedro Ángel Gorostiza para la plaza vacante de caballero page por salida de don Daniel O'Sullivan a capitán del regimiento de infanteria de Hibernia (Registro 01372, Folio 152v).

${ }^{31}$ Era un buen destino. Precisamente cuando en 1789 don Pedro Gorostiza fue ascendido a brigadier y gobernador de Veracruz, el hasta entonces coronel del regimiento de la Corona de Nueva España, el brigadier don Pedro Cambiazo, fue nombrado coronel del regimiento del príncipe (Archivo General de Simancas, Secretaría de Guerra, no 6984-12). 
El caballerizo mayor propuso una terna en los términos habituales. ${ }^{32} \mathrm{El}$ rey no nombró al primero como era usual, ni prefirió a uno de los dos siguientes alterando las expectativas, sino que introdujo directamente la solución: "nombro a D. Pedro Ángel Gorostiza: Está señalado por la Real Mano". (Registro 01372, Folio 181v). El apunte siguiente (f. 181v182), a 24 de junio, trata de la ceremonia ante el rey. El mismo marqués ordena a Juan Andrés del Valle que Gorostiza "se halle en este sitio el sábado 26 por la tarde para ceñirle la espada el domingo 27 por la mañana. Lo que comunico a V. S. para su inteligencia, y que disponga se le den los auxilios que son de práctica". ${ }^{33}$ Esta ceremonia cortesana, tan simbólica, era igualmente usual y tras ella los nuevos capitanes se incorporaban a sus destinos.

Don Pedro Gorostiza, de 16 años, ya es oficial de los ejércitos de su católica majestad, el rey de las Españas, y acaba de entrar en la vida adulta. Cuando estalle la llamada guerra de la Independencia en 1808 ya será un hombre de 22 años y no será el último de su regimiento si es que seguía allí. Pero nada más sabemos de su actividad militar. Quizás haya algún documento, posiblemente en archivos militares, que nos aporte nuevos datos.

También nos queda por saber dónde se formaron sus otros dos hermanos, que, al parecer, también fueron oficiales. En cuanto a lo que se ha venido diciendo del paso de Manuel Eduardo por la Casa de Pajes, no tengo prueba alguna porque no aparece en los registros. Lo que éste dice de sí mismo en la famosa carta a Lucas Alamán de 10 de julio de 1824 —en la que reconoce ser "mexicano, pues" y haber servido "la causa de la libertad europea; y ofrece sus débiles talentos al servicio de la futura prosperidad" de la República_ y que está en el origen de sus diversas biografías es lo siguiente:

Vine a España de edad de cuatro años y apenas alcancé la prevenida por la ordenanza entré a servir como cadete. Capitán ya de granaderos cuan-

${ }^{32}$ Con fecha 18 de junio de 1802, el marqués de Bélgida, para cubrir una vacante en el regimiento de infantería del príncipe, propone tres nombres (Faustino Viana, Manuel Lorfelin, Josef Romero) "que son actualmente en quien concurren las circunstancias de aptitud, edad, estatura, conducta y demás que se requiere para servir este empleo. V. M. en vista de todo se servirá resolver lo que fuere de su agrado" (181v).

${ }^{33}$ Ambos apuntes se repiten en el libro 01370, f.179. 
do la invasión francesa, hice enseguida una gran parte de la guerra de la independencia y creo que con alguna distinción: tuve, sin embargo, que retirarme al cabo, porque ni mis heridas ni la endeblez de mi constitución física me permitieron continuar en ejercicio tan activo (Ortuño: 19).

Lo que Manuel Eduardo procura resaltar es tanto su valentía como su incapacidad para seguir en el ejército. Es posible también que, a la par que insiste en su lucha por la libertad, quiera obviar su vinculación personal con la familia real. ${ }^{34}$ Queda clara su pronta formación militar, pero nada dice de la Casa de Pajes. Jefferson R. Spell, que tanto estudió a Manuel Eduardo y tuvo acceso a los archivos y memoria oral de la familia en México, así lo afirma; y más tarde Lota M. Spell lo mantuvo porque el propio Manuel Eduardo reconoce que conocía desde los 7 años (Lota Spell: 256) a José María Torrijos; y Torrijos, según Alcalá Galiano, se había "educado en la Casa de Pajes del Rey y, por lo mismo, entrado en la carrera militar ya en la clase de capitán” (Alcalá Galiano: 468). Del pasaje de Galiano - que pretende ofrecer dos caras de la emigración liberal a Inglaterra en $1824^{35}$ - sólo podríamos deducir que los Gorostiza, como Torrijos, representaban la "fina crianza y modelos amables" propios de la aristocracia. No conocemos el lugar de su educación primaria — donde estaría también su hermano Pedro Ángel hasta noviembre de 1798 - ni el de su formación militar como cadete. No sabemos dónde servía como capitán de granaderos a sus 19 años cuando el ejército francés se reveló como invasor y no como aliado. Creo necesario documentar las afirmaciones recibidas de Manuel Eduardo, tanto las que él hiciera en sus escritos como las transmitidas por sus descendientes.

Tenemos un enorme hueco documental sobre Pedro Gorostiza entre 1802 y 1827. En este año es nombrado, tras oposición, catedrático de

${ }^{34}$ Esto podría explicar que no citara su hipotética condición de caballero-paje del Rey, que solía ser alegado como mérito o vanagloria. Nada dice de sus homenajes poéticos, cuando era periodista en Madrid, a la "clemente" reina Isabel. Siempre son esperables pequeños olvidos o inexctitudes en razón de la causa misma que se mantiene o de los simples fallos de la memoria. Por ejemplo, cuando Manuel Eduardo vino a Espańa tenía cinco ańos y medio, y no cuatro.

35 "Torrijos, de ilustre familia, nacido, bien puede decirse, en la corte, educado en la Casa de Pajes [...] Francisco Javier Mina, por el contrario, oriundo de la clase del pueblo, habiendo recibido en sus primeros años sólo los rudimentos de la educación más común [...]” (Alcalá Galiano: 468). 
humanidades del Real Seminario de Vergara, a partir de cuyos documentos - conservados hoy en el archivo municipal de Bergara- sacaremos alguna información retrospectiva. El Real Seminario Patriótico Vascongado, fundado en 1776 en la antigua casa de los jesuitas de Vergara, representaba uno de los focos de la Ilustración y fue visitado y comentado por cuantos se interesaban en las reformas de la enseñanza. Entre sus internos, siempre hubo algún criollo. Nunca gustó a la reacción española. Curiosamente, la ciudad de Vergara [hoy Bergara], tras la ocupación francesa de 1794, constituirá un foco anti-francés, y, ya en la década de 1830 , se señalará como feudo carlista.

En 1827 Pedro Ángel tiene 41 años y lo ignoramos todo de su vida adulta. Se había retirado del ejército en fecha indeterminada sin haber superado el grado de capitán por textos que ahora veremos. Sabemos que había cultivado las letras en esos años de silencio documental por una cita de su hermano Manuel Eduardo. Éste publicó en 1819 una Oda en la muerte de Elisa. ${ }^{36}$ En la página segunda y a modo de lema lleva este texto:

No la puedo apartar de mi memoria

Y el labio dice lo que el alma siente

(Soneto inédito de P. Á. G.)

Sin duda está citando a su hermano Pedro Ángel Gorostiza, que siempre usaba el nombre compuesto y al que sólo años después veremos firmar Pedro a secas. Pero no tenemos otro documento sobre su actividad militar o literaria, o sus relaciones y colaboración con su hermano. Podemos suponer que había colaborado con su hermano en la edición de periódicos en Madrid y que era coautor, cuando no autor, de alguna de las obras atribuidas a su hermano. También le ayudaría en sus tareas literarias en Francia. Finalmente cuando se estrenó en Madrid La casa en $v_{\text {venta }}{ }^{37}$ en 1827, Manuel Eduardo residía en Bruselas o entre Bruselas y Londres, por lo que su agente en Madrid debía ser su hermano Pedro Ángel. Todo ello habría que documentarlo.

${ }^{36}$ En la muerte de Elisa. Oda por don Manuel Eduardo de Gorostiza. Madrid: Imprenta de Burgos, 1819. Plaqueta de 7 páginas. Se conserva al menos en la Biblioteca de El Escorial.

${ }^{37}$ Sobre la traducción conservada en Madrid, véase mi estudio "Manuel Eduardo de Gorostiza, traductor”, en F. Lafarga (ed.), La traducción en España (1750-1830). Lengua, literatura, cultura. Lleida: Universitat, 1999. 507-511. 
Siguiendo el expediente de oposición a la cátedra de literatura (Real Seminario. Expedientes sobre la oposición a las cátedras de sintaxis, literatura y esgrima. Sig. C/072-04) sabemos que el 2 de marzo de 1827 el director general del Real Seminario de Vergara, Domingo Iribe, se dirige al primer secretario de Estado y Despacho - primer ministro de la épo$\mathrm{ca}$ - manifestando la necesidad de su establecimiento de contar con un catedrático de Humanidades del que carece desde 1823. El 31 de mayo ya se publica el edicto impreso de don Domingo de Iribe, director del Real Colegio de Vergara (otro nombre que fluctúa), convocando a "rigurosa oposición" con los siguientes ejercicios:

Primeramente cada Opositor escribirá en el término de veinte y cuatro horas encerrado, y sin más auxilio que el de un escribiente y los libros que necesite, dos breves composiciones castellanas, una en prosa y otra en verso sobre los asuntos que respectivamente contuviere la cédula que haya elegido entre las tres que él mismo sacará por suerte. Concluidas las veinte y cuatro horas se harán copias para el presidente y los Censores, y al día siguiente recitará en público el Opositor ambas composiciones, y satisfará a las preguntas y objeciones que sobre cada una le harán los jueces sin limitación de tiempo.

$2^{\circ}$ Realizados los primeros ejercicios, cada Opositor, en el día que le tocare, traducirá de repente el pasaje que elija entre los tres que por suerte le salgan en los dos Autores clásicos latinos, uno en prosa y otro en verso que los jueces le hayan señalado, y responderá a las observaciones que sobre su traducción le hagan dos de sus Coopositores por espacio de un cuarto de hora cada uno.

$\mathrm{Al}$ edicto se le dio la máxima publicidad por toda Espańa. Celebrada la oposición en Madrid, el 15 de noviembre el ministro González Salmón comunica al director Iribe la real orden:

Conformándose el Rey N. S. con la propuesta hecha por la Inspección general de Instrucción pública del Reyno, se ha servido nombrar a D. Pedro Gorostiza propuesto por unanimidad en primer lugar por la misma, Catedrático de Humanidades de ese Real Seminario con la dotación correspondiente.

En cuanto a nuestro protagonista, nos queda por saber cómo tuvo noticia y dónde se encontraba, así como si se conservan en algún sitio 
(quizás el Archivo General de la Administración) los ejercicios de la oposición o al menos el memorial que tuvo que presentar en la secretaría de la Inspección al presentarse como aspirante. Retengamos también la unanimidad en la propuesta que indica la calidad de sus composiciones, lo que nos lleva a otra pregunta: ¿dónde y cómo se realizó el concurso de oposición?

Por último, optar a este puesto de trabajo, ¿significa conformidad con el poder absoluto? En todo caso, tras la dura represión de $1823,{ }^{38}$ Fernando VII fue comprobando la imposibilidad de acceder a las más duras exigencias de la reacción. Y mientras este grupo se encaminaba ya a la formación de un partido que luego llamaremos "carlista", el rey empezó a buscar apoyos en sectores moderados que admitiesen su ejercicio del poder absoluto.

Aunque carecemos de los ejercicios de oposición, sí tenemos algunos frutos en verso y prosa de su ingenio como parte obligada de su trabajo para las celebraciones oficiales (A. Municipal de Bergara. Real Seminario. Planes, programas y discursos. Sig. C/106-07). Son cuatro discursos, una oda y otras composiciones menores. Están fechados entre marzo de 1828 y octubre de 1830. El último testimonio de esta tarea oficial de don Pedro es un Breve Discurso [... para la apertura del curso el día $1^{\circ}$ de octubre de 1830. En sus casi siete cuartillas empieza por cantar la belleza y utilidad de las ciencias en la mejor tradición ilustrada, para pasar a incitar a los alumnos a aprovechar el tiempo, a huir de la humillación — “Qué suplicio tan terrible!”- del indolente en contraste con el triunfo para el aplicado y virtuoso, etc. Para el seguimiento de la ideología que destila ese discurso destacaremos la siguiente idea: entre los efectos de la ignorancia y los conocimientos superficiales e inexactos alude a una ciencia abstracta, "de engañosa aplicación", que separó "la política de la religión y de la moral", que prescindió del "carácter y costumbres de las naciones", y que ha puesto a España y a las demás naciones "al borde del precipicio". Como vemos, todo un libelo anti-liberal basado en la mala comprensión de la filosofía de la Ilustración como ya habían hecho La Harpe y otros en Francia al sentirse libres de los tiranos revolucionarios. Celebra en cambio dos sucesos positivos: el " 70 aniversario de la libertad

${ }^{38}$ En 1823 Fernando VII, rey perjuro, es repuesto en su poder absoluto por los Cien Mil Hijos de San Luis, vergonzosa intervención extranjera en la que no gusta de insistir la historiografía española. 
del Rey, quien volvió a entrar en la plenitud de sus prerrogativas", ${ }^{39}$ y el próximo parto de la Reina que viene a "coronar nuestras dichas". Termina recordándoles a los "seminaristas de Vergara" que "os preciáis de espańoles nobles que por su estado" están obligados a servir a ese heredero y que ninguno habrá que calcule esfuerzos y sacrificios "cuando se trata de cumplir con su deber".

Del conjunto de estos discursos sacamos la impresión que Pedro Ángel Gorostiza no sólo cumple una faceta de su trabajo como catedrático del Real Seminario con total adhesión pública a la ortodoxia ideológica del momento, sino que trasluce su propia adhesión a las reformas moderadas. Pero Fernando no era ningún adalid de las reformas ilustradas, ni rápidas ni lentas, como el mismo don Pedro debía saber por su realidad de profesor malpagado en una institución ilustrada abandonada sin recursos.

No tenemos discursos posteriores a octubre de 1830 porque quizás don Pedro Gorostiza abandonó el Real Seminario aquel mismo curso. Sabemos, al menos, que éste solicita un nuevo empleo en Madrid desde octubre de 1829. Tras dos años de dedicación y visto que no le pagaban, D. Pedro buscó otro trabajo antes de cumplir más años. El expediente (A. Municipal de Bergara. Real Seminario. Expedientes de Personal. Sig: C/100-03) contiene mucha información sobre nuestro protagonista, la institución y la época. El 27 de octubre de 1829 don Pedro dirige al rey esta solicitud:

Señor:

Don Pedro Gorostiza, Caballero Paje que fue del Augusto Padre de V. M. y Capitán de Infantería, actualmente Catedrático de Humanidades del Real Seminario de Nobles de Vergara, con nombramiento de V. M.

A V. M. con el más profundo respeto expone:

Que el estado en el que se halla dicho Seminario hace que solamente se pueda pagar a los profesores las dos terceras partes del sueldo, por lo que el suplicante se ve reducido a menos de quinientos ducados al año, cuando los meros preceptores de latinidad de muchos pueblos de España disfrutan de setecientos u ochocientos; sin otras utilidades, que no hay en Vergara.

${ }^{39}$ El 1 de octubre de 1823 se cierra el Trienio liberal y vuelve Fernando a su poder absoluto. 
Una desproporción tan grande, entre la cantidad y calidad del trabajo del suplicante y el premio que le proporciona, se hace tanto más sensible cuanto que ni su destino es carrera ni puede esperar ascensos; y aún la jubilación que han obtenido algunos a costa de cerca de medio siglo de ímprobos afanes, cada día se presenta más difícil de conseguir; y, por descontado, para el suplicante es totalmente nula: porque tiene 43 ańos de edad y sólo hace dos que profesa en el Seminario.

Por otra parte, durante su larga residencia en Francia, y después, el suplicante no se ha limitado al estudio de las Humanidades, sino que ha procurado instruirse en la Economía Política y Administración; y en los ramos de Matemáticas, que les sirven de apoyo. Y, como según lo indica la ilustrada tendencia del Ministerio de V. M., acaso no tardará en promoverse la Estadística general del Reino, base la más sólida de todo sistema Político, Administrativo y Militar; y para todo esto habrá de formarse en la Corte una Dirección superior, con las oficinas correspondientes:

A V. M. rendidamente suplica

Que por un efecto de su Real Piedad se digne compadecerse de un antiguo y desgraciado criado de su casa, y mandar que se le coloque en otra Dirección u oficinas, si llegan a establecerse; y si esto no, en cualquier empleo proporcionado a sus circunstancias que se halle vacante. Gracia que espera merecer del benigno corazón de V. M. Vergara 27 de octubre de 1829.

Señor.

P. A. L. P. D. V. M. Su humilde vasallo. Pedro Gorostiza. ${ }^{40}$

De este modo quedamos enterados de su edad — que confirma el nacimiento en 1786- y de su larga residencia en Francia. Pero no sabemos dónde ni cuando ni por qué, lo que nos invita a rebuscar en los archivos franceses, sean los nacionales en el Marais o los departamentales, pues en todos ellos quedan testimonios de los emigrados españoles. Debe estar soltero porque no alude nunca a cargas familiares. También sabemos de su dedicación al estudio en la mejor tradición ilustrada, y de su infortunio, porque se llama a sí mismo "desgraciado". Lo que nos invita a buscar explicación y fecha de su exclusión del ejército. ${ }^{41}$

Tenemos constancia de un nuevo empleo para Pedro Ángel en aquel mismo verano de 1833 y, posiblemente, gracias a la ayuda de Zea Ber-

\footnotetext{
${ }^{40}$ Es literal; sólo he modernizado parcialmente la puntuación y ortografía.

${ }^{41}$ Si hubiese sido excluido en una depuración por liberal, ¿por qué se le permite la docencia en Vergara y no su reincorporación a la infantería?
} 
múdez, primer secretario de estado desde octubre de 1832. La ocasión la proporcionó un incidente, casi un diktat, de Inglaterra a propósito de los negros esclavos de Cuba. Se creó una Junta bajo la presidencia de don José de Heredia para examinar el tema de los negros libertos y Gorostiza fue encargado de su secretaría. ${ }^{42}$ En este destino madrileño le llegó a nuestro Pedro Ángel la noticia de la muerte del rey (septiembre de 1833) y las primeras andaduras de la regencia de María Cristina. Este empleo - que no debía ser muy agobiante, porque no he visto ni una sola opinión en el expediente- le duró unos meses, hasta abril del 34, cuando fue nombrado, ipor fin!, redactor de la Gaceta de Madrid con 11000 reales de sueldo, según nos informa el propio interesado. ${ }^{43}$ Heredia propuso al nuevo ministro su cese ${ }^{44}$ y el cese de Gorostiza determinó también la disolución ${ }^{45}$ de esta Junta, al parecer inoperante, cuyo fruto principa ${ }^{46}{ }^{4}$ resultó ser el proporcionar un empleo en Madrid a don Pedro Gorostiza. ${ }^{47}$

Nos queda por estudiar la vida privada de nuestro Pedro Ángel desde este abril de 1834 hasta su muerte en fecha indeterminada pero posterior al 38 en que murió para la literatura. Tampoco sabemos si llegó a adoptar otro nombre en sus trabajos literarios. Lo dejamos como redactor de la Gaceta, el diario oficial de la época. No sabemos si allí o en los archivos de protocolos notariales se encuentran dormidos nuevos datos. ${ }^{48}$

${ }^{42}$ AHN (Archivo Histórico Nacional de Madrid), Sección Estado, 8020/2-Leg.

${ }^{43}$ Es el documento no 10, un oficio autógrafo dirigido a don José de Heredia, fechado a 2 de abril de 1834. "Excmo. Sr.: El Administrador de la Real imprenta me avisa con fecha de 31 de marzo último que $S$. M. ha tenido a bien nombrarme tercer redactor de la Gaceta de Madrid con el sueldo de once mil reales anuales; lo que pongo en conocimiento de V. E. para su conocimiento y los efectos que estime convenientes".

${ }^{44}$ Con fecha de 19 de abril de 1834 (n ${ }^{\circ} 11$ ), Heredia propone a Martínez de la Rosa, el nuevo primer secretario de estado, que Gorostiza cese "en el goze de la asignación de 9000 reales, si S.M./ tiene a bien dar por concluido el negocio que cometió a la junta; o reducirla a 6000 según está mandado por regla general" (1 verso/2 recto).

45 Una nota al margen del documento anterior (11, recto) indica que la Junta se disuelve, que pase el asunto al Consejo de España e Indias; que se agradezca a presidente y vocales y que "cese el secretario en virtud de su nuevo destino".

${ }^{46}$ Heredia da a entender ( $\left.\mathrm{n}^{\circ} 11\right)$ que se creó para dar el empleo a Gorostiza.

${ }^{47}$ El documento no 12 y último es un borrador (con tachones y sin firma) de la real orden de cese de Gorostiza firmado en Aranjuez a 21 de abril.

${ }^{48}$ Suponiendo que murió en Madrid, el rastreo de los libros de defunción de las diferentes parroquias nos puede ofrecer la fecha exacta de su muerte. Ni el Archivo General de la Administración (Alcalá), ni el Archivo Militar (Segovia) contienen expedientes con su nombre. 
Como conclusión diremos que Pedro Gorostiza es testigo de una época en lo literario y en lo personal. La familia paterna representa bien a aquellos hidalgos de la más vieja España que, obligados a emigrar, eligieron las armas al servicio del rey. La materna, al patriciado urbano de la ciudad más rica, cultivada y abierta de España. Su padre ascendió y se labró una carrera por sus propios méritos y esfuerzos, que a su vez fueron recompensados por el buen gobierno de Carlos III. Su madre brilló desde joven por su instrucción y durante toda la vida dedicó sus ocios a la cultura. En esta familia Pedro Ángel — sin bienes de fortuna pero protegido por el rey- fue destinado y educado para servir en los ejércitos de la monarquía hispánica. En la Casa de Pajes recibió una amplia instrucción humanística —científica y literaria- y cortesana. Tanto allí como en la sociedad madrileña que frecuentaba su madre, fue adquiriendo los finos modales de la alta sociedad. Ingresado en el regimiento del príncipe a los 16 años, abandona el ejército —en fecha indeterminada, pero que debió ser temprana, y por causa desconocida - sin superar el grado de capitán. Sin embargo siguió cultivando el estudio y las letras. Nada sabemos de su actividad entre 1808 y 1814, durante la llamada "Guerra de la Independencia”. Pasó años en Francia, lo que le permitió profundizar en una lengua, literatura y cultura que todo español instruido de su época conocía en mayor o menor grado. Sospechamos que colaboró en las tareas literarias de su hermano Manuel Eduardo. No sabemos de qué vivía.

Ya a los 41 años, en 1827, ganó por oposición la cátedra de humanidades del otrora floreciente seminario de Vergara. Se sintió orgulloso de su empleo, así como de su condición de antiguo caballero-paje. El impago de su sueldo y la falta de perspectivas, lo impulsó a abandonar un trabajo en el que se sentía cómodo y que desempeñaba con "capacidad y celo", y a buscar otro en Madrid. Aparece en la vida literaria madrileña en 1833 defendiendo la recién estrenada comedia Contigo pan y cebolla que había escrito su hermano, ausente de España desde hacía casi 10 años. Aquel mismo verano consiguió otro empleo en la administración civil, empleo que abandona meses después cuando alcanzó un puesto de redactor en la Gaceta de Madrid, diario oficial de la época. De 1835 a 1838 , en plena batalla romántica, participa en la vida teatral madrileña como traductor habilidoso y autor original. Suya es la versión de la primera pieza de Victor Hugo estrenada en Madrid. En sus tres piezas traducidas, representantes de otros tantos subgéneros del momento, de- 
muestra su dominio de la prosa y versificación castellanas al tiempo que suprime o suaviza los elementos más chirriantes para sus espectadores. En 1838 vuelve a desaparecer para la literatura. Tiene 52 años ¿Qué ha sido de él?

Por otra parte la separación y suerte distinta de los dos hermanos Gorostiza simbolizan perfectamente el drama íntimo de aquella generación ilustrada de españoles de ambos hemisferios ante la disolución del antiguo régimen y la asunción de su libertad y soberanía. 


\section{BibLIOGRAFÍA}

Alcalá Galiano, Antonio. Recuerdos de un anciano, Madrid: Navarro, 1878.

Ancelot, Marguerite-Virginie. Marie ou Trois époques, comédie en trois actes, en prose, par Mme Ancelot... Paris: Magasin Théâtrale, 1836.

Caldera, Ermanno. "La Lucrecia Borgia que se estrenó en el Teatro del Príncipe”, en Lafarga, Palacios y Saura (eds.). Neoclásicos y románticos ante la traducción, Murcia: Universidad de Murcia, 2002. 245-253.

Calderón Quijano, José A. (dir.). Virreyes de Nueva España en ele reinado de Carlos IV. Tomo I, 1787-1798. Sevilla: Escuela de Estudios Hispano-Americanos, 1972.

Cejador y Frauca, Julio. Historia de la lengua y literatura castellanas. Madrid: Gredos, 1972. [Primera edición 1915-1922].

Cepeda, Ángel. Lucrecia Borgia. [Drama en cinco actos, escrito en francés por Victor Hugo. Traducido libremente al castellano por don Ángel Cepeda. Representado por primera vez en el Teatro del Príncipe en 18 de julio de 1835]. Madrid: Repullés, 1835.

- Defensa de la Comedia intitulada Contigo pan y cebolla, contra las críticas que han hecho de ella los periódicos de Madrid. Dirigida a los redactores de la Revista Espańola por Don Angel de Cepeda. Madrid: Repullés, 1833. (BNE : Sig. VC/2727/29).

Delavigne, Casimir. Louis XI, tragédie en 5 actes et en vers, París: Barba, 1832.

Dowling, John (edición, introducción y notas). Manuel Eduardo de Gorostiza. Contigo pan y cebolla. Valencia: Albatros, 1992.

Gamazo Barrueco, Sara. (Introducción, índices y antología). La Revista Española. Barcelona: ETO-Micropublicaciones, 1989.

González Peña, Carlos. Historia de la literatura mexicana desde los orígenes hasta nuestros días. México: Porrúa [Décima edición, 1966 (Primera edición, 1928)].

Gorostiza, Pedro. El Desconfiado. Comedia original en 5 actos y en verso por D. Pedro Gorostiza. Madrid: Repullés, 1837. [No aparece en los catálogos de la BNE; sí en los de la BNF con 2 ejemplares, 8-YTH-65180 y 8-RE$6176(8,2)$, y una reproducción microfilmada: R 115468. En Madrid la tiene el Ateneo].

Gorostiza, Pedro. Pedrarias Davila. Drama original en cinco actos, de los cuales el cuarto está dividido en dos cuadros, por don Pedro Gorostiza. Madrid: Imprenta Nacional, 1838. [BNE, 3 ejemplares: HA/10939, T/11195, T/ 21087].

Hugo, Victor. Lucrèce Borgia. (Drame, 1833), en Théâtre Complet. Vol. II. Établie et annotée par J.-J. Thierry et Josette Mélèze (éds.). Paris: Pléiade, 1964, 1-409. 
La Abeja. BNE: Micro 0733.

Larra, Mariano José DE. "Primera representación de la comedia nueva de don Manuel Eduardo de Gorostiza titulada Contigo Pan y Cebolla”, en Obras. Vol. I. 4 tomos. Carlos Seco Serrano (ed.). Madrid: Atlas, 1960 (Biblioteca de Autores Españoles).

—. "Réplica al folleto titulado "Defensa de la comedia Contigo Pan y Cebolla”, en Obras. Vol. I. 4 tomos. Carlos Seco Serrano (ed.). Madrid: Atlas, 1960. 268.

LLorens, Vicente. Liberales y románticos, Madrid: Castalia, 1968.

Monguió, Luis. "Manuel Eduardo de Gorostiza, director de periódicos en Madrid, 1820-1921", en Homenaje a Rodríguez Moñino. Vol. I. 2 vols. Madrid: Castalia, 1966. 413-424.

Ortuño, Manuel. Manuel Eduardo de Gorostiza, hispano-mexicano, romántico y liberal. Madrid: Ayuntamiento, 1988.

Revista Española-El Mensajero de las Cortes. 9 Tomos. BNE: Micro 0360.

Rodríguez Plaza, Joaquina. "Notas sobre la vida y obra de Manuel Eduardo de Gorostiza”, en En torno a la literatura mexicana. México: Universidad Autónoma Metropolitana, 1989. 11-30.

Saura, Alfonso. "Pedro Gorostiza y Cepeda, traductor", en La lingüística francesa en el nuevo milenio. Figuerola, Parra y Solà (eds.). Leida: Milenio, 2002. 707-716.

Spell, JefFerson Rea. "Some little known plays of Gorostiza", en The Romanic Review. Vol. XXIII. 1 (1932). 138-141.

Spell, JefFerson ReA. "Introducción", inédito para la edición de las obras de Manuel Eduardo de Gorostiza. ${ }^{49}$

Spell, Lota May. "Notes on Gorostiza", en Hispanic American Historical Review, vol. 38 (1958). 256-259.

Veinticuatro Diarios (Madrid, 1830-1900). Artículos y noticias de escritores españoles del siglo xIx, por el Seminario de Bibliografía Hispánica de la Facultad de Filosofía y Letras. 4 vols. Madrid: Consejo Superior de Investigaciones Científicas, 1968-1975.

${ }^{49}$ Agradezco y debo su comunicación al Dr. D. Felipe Reyes Palacios, profesor de la Universidad Nacional Autónoma de México. 